\title{
Association of Serum Antioxidant Enzymes and Nervous Tissue Markers in Hypertensive Patients
}

\author{
Marisol Peña-Sánchez¹, Sergio González-García1, Gretel Riverón-Forment ${ }^{2}$, \\ Otman Fernández-Concepción' ${ }^{1}$, Olivia Martínez-Bonne ${ }^{2}$, Gisselle Lemus-Molina², \\ Isabel Fernández-Almirall ${ }^{1}$, María de la Caridad Menéndez-Sainz ${ }^{1}$, \\ Alina González-Quevedoㅁ, Janis T. Eells ${ }^{3}$ \\ ${ }^{1}$ Institute of Neurology and Neurosurgery, Havana, Cuba \\ ${ }^{2}$ National Genetic Center, Havana, Cuba \\ ${ }^{3}$ College of Health Sciences, University of Wisconsin-Milwaukee, Milwaukee, USA \\ Email: marisol.pena@infomed.sld.cu
}

Received 4 March 2014; revised 6 April 2014; accepted 15 April 2014

Copyright (C) 2014 by authors and Scientific Research Publishing Inc.

This work is licensed under the Creative Commons Attribution International License (CC BY). http://creativecommons.org/licenses/by/4.0/

\section{Open Access}

\section{Abstract}

Background and Purpose: Hypertension has serious effects on cerebral blood vessels. Oxidative stress seems to be implicated in blood pressure elevation, through increased reactive oxygen species and/or decreased antioxidant capacity. Recently blood markers indicating damage to the central nervous system were reported to be increased in hypertensive patients. However, it is unknown whether antioxidant capacity is related to these changes. This study was designed to explore if the concentration of blood markers for nervous tissue damage was associated to antioxidant capacity in hypertensive patients. Methods: Twenty hypertensive patients and 23 healthy controls were studied. They were paired by age, sex, ethnicity, or risk factors. Serum neuron specific enolase (NSE) and S100 calcium binding protein B (S100B) were measured as nervous tissue damage markers, as well as the activity of antioxidant enzymes (catalase, glutathione peroxidase, glutathione reductase and gamma-glutamyltransferase). Results: Serum neuronal specific enolase (NSE) and S100 calcium binding protein B (S100B) concentrations determined by immunoassay were significantly increased in patients vs. controls. The activities of antioxidant enzymes measured by spectrophotometry showed that plasmatic catalase and erythrocytic glutathione peroxidase were significantly increased in patients, but erythocytic catalase was decreased. Gammaglutamyltransferase activity was significantly correlated with $\mathrm{S100B}$ in hypertensive patients, while erythrocytic catalase activity was decreased in subjects with higher NSE levels. Conclusion: This preliminary investigation suggested that antioxidant status might be modulated through changes in antioxidant enzymatic activity in hypertensive patients. The association of some of these 
changes with peripheral markers of damage to the central nervous system could indicate that the increased levels of these proteins in hypertension are partly related to oxidative stress.

\title{
Keywords
}

\author{
Hypertension, Gamma-glutamyltransferase, Catalase, Neuron Specific Enolase, S100 Calcium \\ Binding Protein B
}

\section{Introduction}

Hypertension (HT) is a common disorder which generates vascular impairment (endothelial dysfunction, altered contractility, and vascular remodeling). It is a major risk factor for cerebrovascular, cardiovascular and renal disease [1]. Renin-angiotensin-aldosterone system, G protein-coupled receptor, inflammation and immune factors have been involved in the pathophysiology of HT [1]. All these mechanisms are related to excess reactive oxygen species (ROS). But whether increased ROS levels are cause or consequence of high blood pressure (BP) still remains unclear [2]. On the contrary the role of antioxidant mechanisms in HT is not consistent. Some studies have found decreased activity of antioxidant enzymes [3]-[7] while others report opposing effects [8]-[11].

In cerebral blood vessels, HT may lead to arterial occlusions (atherosclerotic plaques), ischemic injury, lipohyalinosis (arteries and arterioles) and reductions in cerebral blood flow. Cerebrovascular dysfunction might be partly induced via activation of nicotinamide adenine dinucleotide phosphate (NADPH) oxidase, which is one of the main sources of ROS [12].

It was recently reported that patients with essential HT displayed elevated serum levels of protein markers for nervous tissue damage: neuron specific enolase (NSE) and S100 calcium binding protein B (S100B) [13]. Nevertheless, only NSE was related to subclinical damage of CNS demonstrated by magnetic resonance imaging in these patients [13]. The association of NSE and S100B with oxidant/antioxidant content has been reported in few diseases. In bipolar disorder, Andreazza et al. [14] found elevated S100B and superoxide dismutase (SOD) activity —an enzyme scavenger of superoxide anion-both in manic and depressed patients. Also NSE levels were found to be increased in patients suffering cardiac arrest, together with high concentrations of malondialhehyde (MDA), a lipid oxidation product [15]. However, we found no reports relating antioxidant capacity modifications in essential HT with subclinical nervous tissue damage. The objective of this work was to explore if the serum concentration of NSE and S100B was related to antioxidant capacity in hypertensive patients.

\section{Methods}

Twenty patients with different grades of severity of essential HT participated in the present study. Duration of HT was 13 years (5 - 32 years) (median, 10 - 90 percentiles). The severity of essential HT was evaluated according to degree of retinopathy and blood pressure levels previous to blood sampling $(<140 / 90$ and $\geq 140 / 90)$. The HT status of the study sample was assessed by a trained neurologist using standard criteria formulated by the Joint National Committee VII [16]. The mean ( \pm SD) age was $54.1 \pm 6.9$ years. All patients completed an interview aimed to ascertain their personal pathological history and medication used. Those with clinical evidence of known neurological disease, malignancies, chronic degenerative or inflammatory diseases, recent infection or trauma were not included.

The control group was comprised of 23 apparently healthy subjects who volunteered to be included in this study - mean $( \pm S D)$ age was $48.3 \pm 10.9$ years. The normotensive subjects included did not have a known history of neurological, cardiovascular, liver, renal, inflammatory or malignant diseases. Those referring recent infection or trauma were not included. Before blood extraction, BP was measured in patients and controls on the right arm in a seated position after a 5-min rest period, following the recommendations of Perloff et al. [17].

Ten milliliters of blood were drawn by venipuncture from patients and controls and collected in dry tubes and $\mathrm{K}_{3}$ EDTA. Serum S100B and NSE were measured by employing the immunoassay kits CanAg S100B EIA (70810) and CanAg NSE EIA (420-10) from CanAg Diagnostics AB (Sweden). Specifications of the techniques were detailed previously [13].

The activities of antioxidant enzymes were determined in erythrocytes. These were lysed in cold distilled wa- 
ter (1:4) and stored in at $4^{\circ} \mathrm{C}$ for $15 \mathrm{~min}$, subsequently removing the cell debris by centrifugation. Erythrocyte and plasma catalase (CAT) activity were determined in accordance with the method of Aebi [18]. The cytosolic glutathione peroxidase (cGSH-Px) activity was determined in erythrocytes according to Paglia and Valentine [19] and glutathione reductase (GR) activity was measured as described by Carlberg and Mannervik [20]. Their values were expressed as units per milligram of hemoglobin. Serum gammaglutamyltransferase or transpeptidase (GGT) activity was measured according to Pasqualetti et al. [21].

Frequencies of the demographic and clinical variables were calculated. Continuous variables were tested for normal distribution using Kolmogorov-Smirnov test. Normally distributed variables were expressed as mean \pm SD. Associations between categories of variables were measured by the $\chi^{2}$ test and means of continuous data were compared using Student's independent samples t-test. Medians and 10 - 90 percentiles were calculated, and the Mann-Whitney U test was employed to compare groups when the sample size was smaller. Correlations between continuous variables were evaluated by calculating Spearman's coefficient (R). Bonferroni's correction was employed for adjusting the p-values. The "optimum" cut-off values were calculated for each protein by receiver-operating characteristics (ROC) analysis. Statistical calculations were performed with Statistica 8.0 for Windows (Statsoft Inc. 2007). Statistical significance was achieved if $P<0.05$.

\section{Results}

Table 1 shows the demographic and clinical features of the hypertensive and control groups. No significant differences were observed for mean age, gender, ethnicity, or risk factors (diabetes mellitus, alcoholism and smoke) between the control and hypertensive groups. Almost all hypertensive patients had high BP at the moment of blood extraction $(\geq 140 / 90)$. Eighteen patients were receiving antihypertensive treatment; $50 \%$ received one or two antihypertensive drugs, while the other half were on more than two drugs (combined therapy).

The protein markers of nervous tissue damage measured are shown in Table 2. Hypertensive patients had significantly higher serum S100B and NSE concentrations than the control group ( $p=0.016$ and $p=0.02$, respectively).

Enzymatic activity of CAT in plasma was greatly augmented, while CAT in erythrocytes was decreased in patients vs. controls. cGSH-Px activity in erythrocytes was increased in the patient group (Figure 1). Although a trend towards higher GR and GGT was observed in hypertensives with respect to controls, no significant changes were detected (medians: 30.0 vs. $17.5 \mathrm{U} / \mathrm{L}, p=0.053$ and 11.2 vs. $7.37 \mathrm{U} / \mathrm{L}, p=0.870$, respectively). No differences in the activities of antioxidant enzymes were observed between mono and combined antihypertensive therapies in patients after adjusting with Bonferroni's correction.

None of the antioxidant enzymes were associated with the severity of HT measured through degree of retinopathy (0-I vs. II-III) and blood pressure values (<140/90 vs. $\geq 140 / 90)$.

The cut-off values after ROC curve analysis were $11.4 \mu \mathrm{g} / \mathrm{L}$ for NSE (sensitivity $-68.4 \%$ and specificity $-71.4 \%$; AUC: $0.737, \mathrm{p}=0.022$ ) and $76.5 \mathrm{ng} / \mathrm{L}$ for S100B (sensitivity $-76.5 \%$ and specificity $-71.4 \%$; AUC: $0.812, p=0.016$ ). When hypertensive patients were classified according to these cut-off values, significantly lower levels of erythrocytic CAT activity were observed in patients with NSE $>11.4 \mu \mathrm{g} / \mathrm{L}$ (Figure 2(a)); while GGT activity was higher in hypertensive patients with S100B $>76.5<\mathrm{ng} / \mathrm{L}(\mathrm{Z}=2.110, p=0.035)$ (Figure 2(b)). The later was further sustained by calculating Spearman's correlation, which showed a significant correlation between GGT and S100B in hypertensive patients (Figure 3). There were no other significant correlations between antioxidant enzymatic activities, NSE and S100B concentrations.

\section{Discussion}

Hypertensive patients had significantly higher serum S100B and NSE concentrations than the control group, corroborating what our work group had previously reported [13].

Decreased erythrocytic CAT and increased cGSH-Px activities could be related to the inhibition of CAT by the presence of superoxide anions in the biological milieu. This inhibition has been reported to generate a ferroxi-catalase form that has low activity for decomposing hydrogen peroxide [22]; thus cGSH-Px activity could be increased to counteract the high levels of hydrogen peroxide, perhaps through mechanisms of redox regulation.

In the case of pre-hypertensive subjects the elevation of cGSH-Px activity was suggested to be the result of upregulation in order to deal with the excess production of free radicals [9]. In fact Mansego et al. [23] had ob- 
Table 1. Demographic and clinical characteristics of hypertensive and control groups.

\begin{tabular}{|c|c|c|c|c|}
\hline \multicolumn{2}{|c|}{ Parameters } & $\begin{array}{l}\text { Hypertensive } \\
(\mathrm{N}=20)\end{array}$ & $\begin{array}{l}\text { Controls } \\
(\mathrm{N}=23)\end{array}$ & $p$-value ${ }^{*}$ \\
\hline \multicolumn{2}{|c|}{ Mean Age \pm SD } & $54.1 \pm 6.9$ & $48.3 \pm 10.9$ & 0.205 \\
\hline \multicolumn{2}{|c|}{ Gender F/M } & $10 / 10$ & $15 / 8$ & 0.313 \\
\hline \multicolumn{2}{|c|}{ Race W/M/B } & $11 / 2 / 7$ & $14 / 6 / 3$ & 0.152 \\
\hline \multicolumn{2}{|c|}{ Diabetes mellitus (yes/no) } & $5 / 15$ & $1 / 22$ & 0.037 \\
\hline \multicolumn{2}{|c|}{ Alcohol (yes/no) } & $4 / 16$ & $2 / 21$ & 0.232 \\
\hline \multicolumn{2}{|c|}{ Smoke (yes/no) } & $8 / 12$ & $7 / 16$ & 0.377 \\
\hline \multirow{2}{*}{$\begin{array}{l}\text { Blood pressure } \\
\quad(\mathrm{mm} \mathrm{Hg})\end{array}$} & $<120-140 / 80-90$ & 5 & 22 & - \\
\hline & $\geq 140$ - 159/90 - 99 & 15 & 1 & - \\
\hline \multirow{2}{*}{ Retinopathy degree } & $0-\mathrm{I}$ & 6 & - & - \\
\hline & II-III & 14 & - & - \\
\hline \multicolumn{2}{|c|}{ Monotherapy } & 9 & - & - \\
\hline \multicolumn{2}{|c|}{ Combined therapy } & 9 & - & - \\
\hline \multicolumn{2}{|c|}{ Without therapy } & 2 & 23 & - \\
\hline
\end{tabular}

${ }^{*}$ Chi-Square test, $p<0.05$. W/M/B: White/“Mulato”/Black.

Table 2. Serum NSE and S100B levels in hypertensive patients and controls.

\begin{tabular}{cccc}
\hline $\begin{array}{c}\text { Proteins } \\
\text { (means; min-max) }\end{array}$ & Hypertensive & Control & \\
\hline NSE $(\mu \mathrm{g} / \mathrm{L})$ & $15.7(3.9-29.2)$ & $11.0(3.1-22.3)$ & $2.2 / 0.028$ \\
S100B $(\mathrm{ng} / \mathrm{L})$ & $104.2(51.0-210.4)$ & $53.9(20.5-80.9)$ & $2.4 / 0.014$ \\
\hline
\end{tabular}

Mann Whitney test, $p<0.05$. Abbreviations: NSE, neuron specific enolase; S100B, S100 calcium binding protein B.

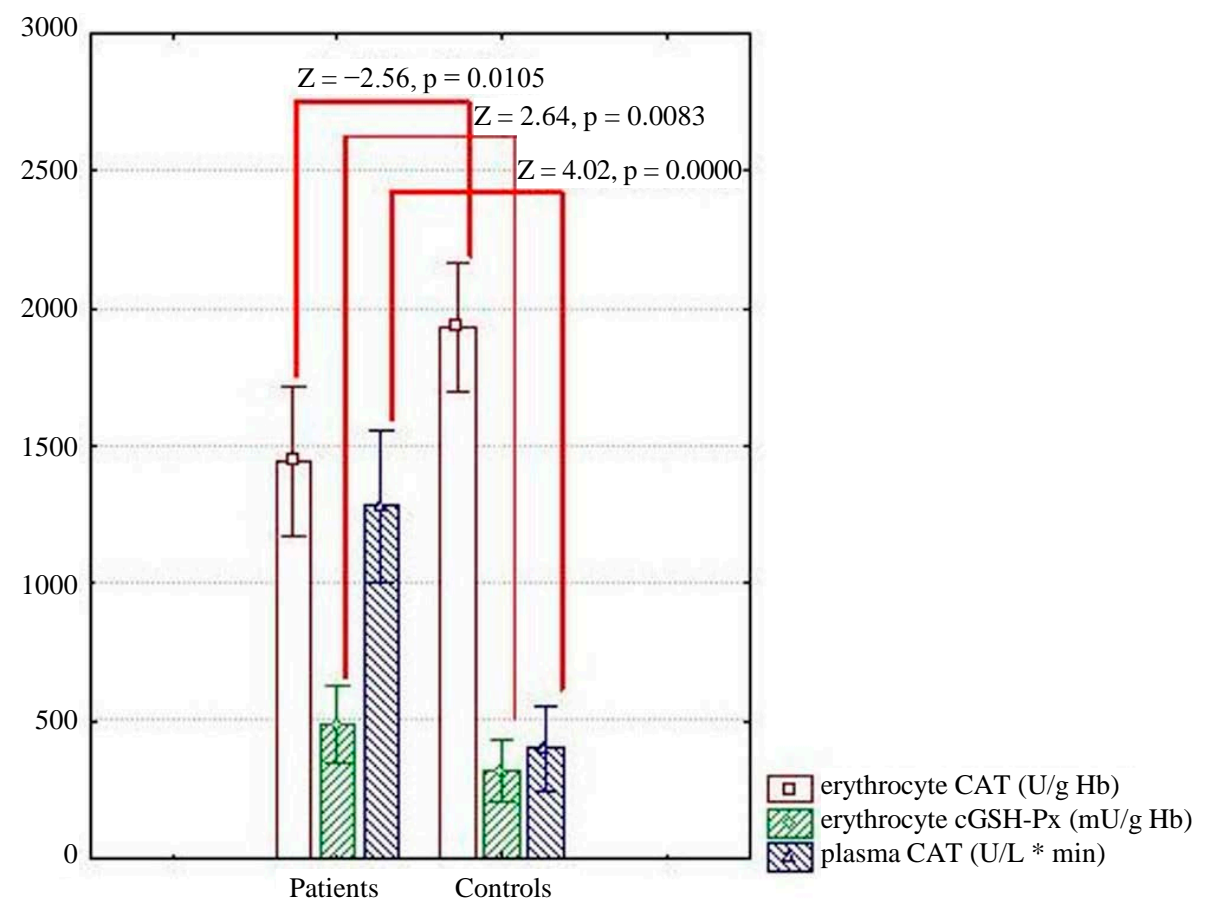

Figure 1. Activities of CAT (erythrocyte and plasma) and cGSH-Px (erythrocyte) in hypertensive patients and control group ( $p<0.05$, Mann-Whitney). Abbreviations: CAT, catalase; cGSH-Px, cytoplasmatic glutathione peroxidase. 


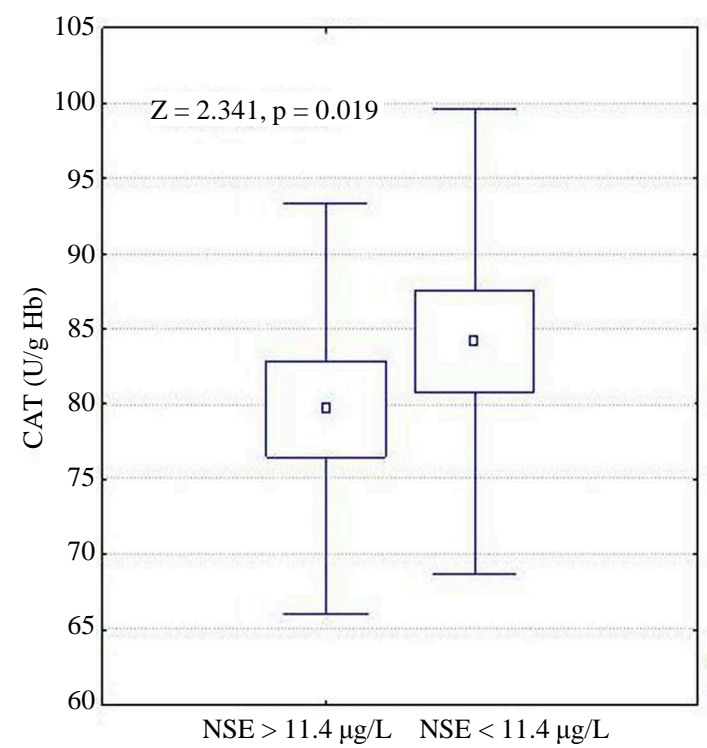

(a)

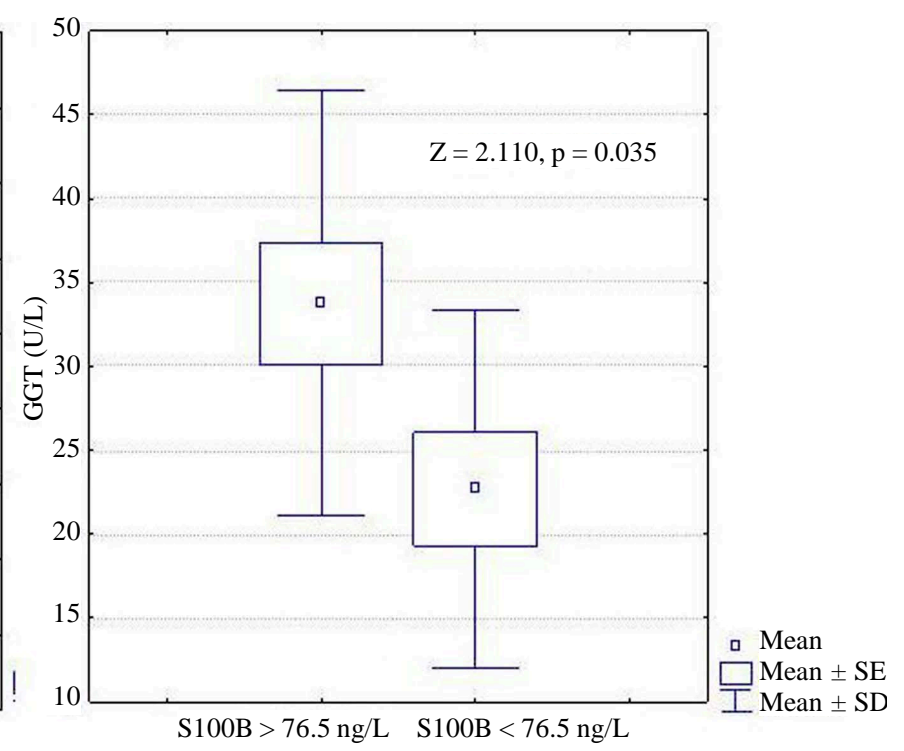

(b)

Figure 2. Enzymatic activities of (a) CAT and (b) GGT according to NSE and S100B cut off levels, respectively ( $p<0.05$, Mann-Whitney). Abbreviations: CAT, catalase; NSE, neuronal-specific enolase, GGT, gammaglutamyltransferase or transpeptidase; S100B, S100 calcium binding protein B.

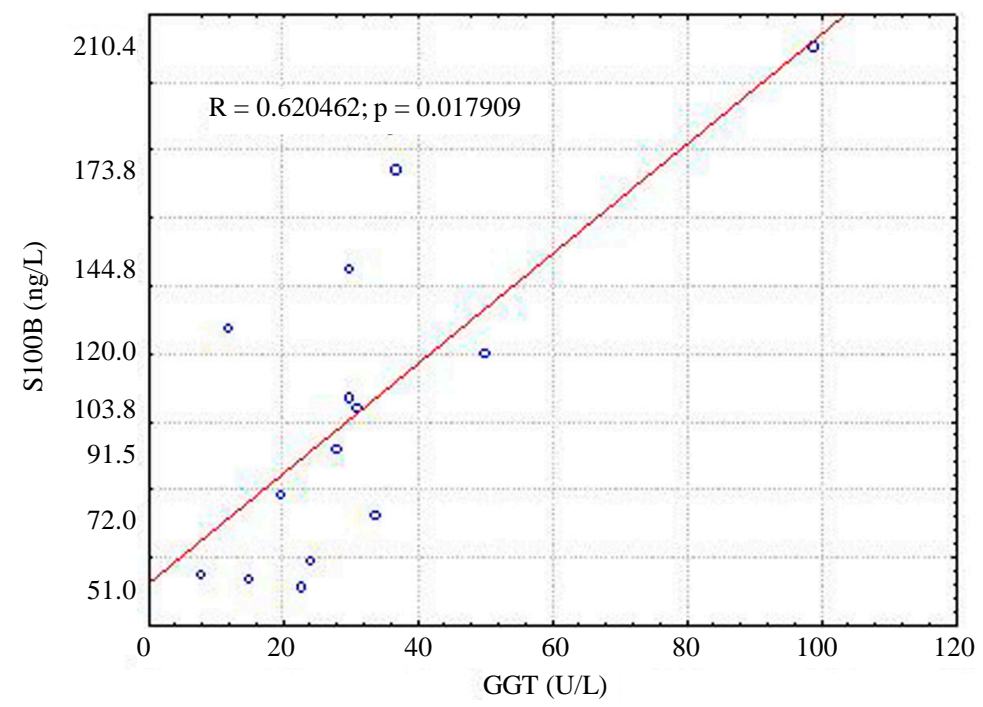

Figure 3. Correlation between GGT and S100B in hypertensive patients employing Spearman's coefficient. Abbreviations: GGT, gammaglutamyltransferase; S100B, S100 calcium binding protein B.

served a significant association between the CC genotype of the c.-891C > T (rs3448) polymorphism in the cGSH-Px gene and high values of 8-oxo-2'-deoxyguanosine (8-oxo-dG) in the mononuclear cells of hypertensive patients; which was also associated to cGSH-Px activity. Similar findings were described for glutathione Stransferase (GST), where increased GST activity was suggested to compensate the decreased activity of cGSHPx in the blood of elderly patients with essential HT [24]. GST mu-1 (M1) and GST theta-1 (T1) gene polymorphisms (GSTM1-ve and GSTT1-ve respectively) also seem to predict development of essential HT in Egyptian individuals with this pathology [5]. Conversely, in our study the activities of GR and GGT (enzymes involved in the GSH cycle) were not altered in hypertensive patients. Although we could not measure the expression of genes in antioxidant enzymes, these results could be a response to the increased cGSH-Px activity.

Impaired enzyme expression response and enzyme inactivation in conditions of oxidative stress are arguments 
which could explain these changes [25]. Nevertheless, it should be taken into account that antihypertensive treatments have been reported to enhance the activity of these enzymes [25]-[27], and to reduce the state of oxidative stress [28]-[30]. Furthermore, some antihypertensive drugs seem to have antioxidant effects per se [31]. In the present study we could not exclude this effect, as only 2 patients were not receiving antihypertensive medication. Nevertheless, we analyzed the possible effect of antihypertensive drugs on antioxidant enzyme activities comparing patients who were receiving one or two drugs with those receiving combined therapy, and found no differences between these two therapeutic groups after adjusting with Bonferroni's correction. Although this does not exclude the possibility of our results being influenced by therapy, it indicates at least that multi-medication does not seem to enhance this effect, if present.

The association of blood markers for CNS damage and oxidative stress has been explored in treatment refractory schizophrenics and in individuals who had suffered cardiac arrest, where increased NSE and lipid peroxidation (MDA and 4-hydroxinonenal, 4-HNE) concurred [15] [32]. Medina-Hernández et al. [33] suggested that elevated MDA and 4-HNE might alter the permeability of the neuronal cytoplasmic membrane, consequently facilitating the release of NSE. Considering that oxidative damage has been documented in essential HT and extrapolating these results to the erythrocyte, the low activity of erythrocytic CAT and the increase of serum NSE detected in our study could be due to their release from erythrocytes during oxidative injury [8] [34]; although increased serum NSE in hypertensive patients could also be originating from the CNS as we previously suggested [13].

The CAT gene has been studied in essential HT, showing polymorphisms in its promoter region, c.-844A > G (rs769214) and c.-262T > C, which are related with BP and essential HT, respectively [32] [35]. Recently the T allele of the c.-20C > T (rs1049982) polymorphism in the CAT gene was associated with significantly lower values of either systolic BP or diastolic BP and with the risk for HT [23].

On the other hand, the association encountered between GGT activity and blood concentration of S100B is of interest. GGT is an enzyme that participates in the transfer of degraded glutathione, for in its reincorporation into the synthesis of glutathione and has also been suggested to be a marker of oxidative stress [36]. Its increased activity in plasma or serum has been related with BP in HT and to risk of cardiovascular and cerebrovascular diseases [37]-[39]. Some authors have suggested that this elevation could be aimed at increasing intracellular glutathione in order to compensate oxidative stress [40] [41]. Although we have not encountered information in the scientific literature associating directly GGT activity and S100B, there are two possibilities to consider: 1) this association could be related to mechanisms originating in the nervous system, and/or 2) the increase of S100B could be related to altered oxidative mechanisms in the periphery which have been reported in HT.

There are some findings which support the association of S100B and oxidative mechanisms in the nervous system. Serum GGT activity and sciatic nerve S100B immunoreactivity were found to be elevated in an experimental model of hyperglycemic neuropathy [42]. Other authors have shown that astrocytes respond to changes in oxygen pressure with reactive gliosis, leading to increased S100B levels [43]. On the other hand, blood S100B can originate from non cerebral sources (renal cells, myoblasts, skeletal muscle cells, skin Langerhans cells) [44]; thus, its association with peripheral oxidative mechanisms is also possible. Some findings support this hypothesis, as S100B was found to correlate with total thiols in the serum of children with bacterial meningitis [45]. Moreover, in preeclampsia (characterized by HT in pregnancy), Tskitishvili et al. [46] demonstrated increased S100B expression in villous and amniotic tissues under oxidative stress and S100B induction of endoglin (an accessory protein of the transforming growth factor- $\beta$, TNF- $\beta$ ) in endothelial cells, leading to endothelial dysfunction.

Considering these results, the simultaneous determination of serum GGT activity and S100B should be further investigated to elucidate their possible prognostic value in HT.

\section{Conclusion}

This preliminary investigation shows that antioxidant status is modulated through changes in antioxidant enzymatic activity in hypertensive patients. The association of some of these changes with peripheral markers of damage to the CNS has never been explored, and could indicate that the increased levels of these proteins in HT could be partly related to oxidative stress.

\section{References}

[1] Briones, A.M. and Touyz, R.M. (2010) Oxidative Stress and Hypertension: Current Concepts. Current Hypertension 
Reports, 12, 135-142. http://dx.doi.org/10.1007/s11906-010-0100-z

[2] Ward, N.C., Hodgson, J.M., Puddey, I.B., Mori, T.A., Beilin, L.J. and Croft, K.D. (2004) Oxidative Stress in Human Hypertension: Association with Antihypertensive Treatment, Gender, Nutrition, and Lifestyle. Free Radical Biology \& Medicine, 36, 26-32. http://dx.doi.org/10.1016/j.freeradbiomed.2003.10.021

[3] Khullar, J., Relan, V. and Sherawat, B.S. (2004) Antioxidant Activities and Oxidative Stress by Products in Human Hypertension. Hypertension, 43, e7-e8. http://dx.doi.org/10.1161/01.HYP.0000111210.34843.b6

[4] Tandon, R., Sinha, M.K., Garg, H., Khanna, R. and Khanna, H.D. (2005) Oxidative Stress in Patients with Essential Hypertension. National Medical Journal of India, 18, 297-299.

[5] Bessa, S.S., Ali, E.M. and Hamdy, S.M. (2009) The Role of Glutathione S-Transferase $M_{1}$ and $T_{1}$ Gene Polymorphisms and Oxidative Stress-Related Parameters in Egyptian Patients with Essential Hypertension. European Journal of Internal Medicine, 20, 625-630. http://dx.doi.org/10.1016/j.jim.2009.06.003

[6] Amirkhizi, F., Siassi, F., Djalali, M. and Foroushani, A.R. (2010) Assessment of Antioxidant Enzyme Activities in Erythrocytes of Pre-Hypertensive and Hypertensive Women. Journal of Research in Medical Sciences, 15, 270-278.

[7] Kashyap, M.K., Yadav, V., Sherawat, B.S., Jain, S., Kumari, S., Khullar, M., et al. (2005) Different Antioxidants Status, Total Antioxidant Power and Free Radicals in Essential Hypertension. Molecular and Cellular Biochemistry, 277, 89-99. http://dx.doi.org/10.1007/s11010-005-5424-7

[8] Simic, D.V., Mimic-Oka, J., Pljesa-Ercegovac, M., Savic-Radojevic, A., Opacic, M., Matic, D., et al. (2006) By Products of Oxidative Protein Damage and Antioxidant Enzyme Activities in Plasma of Patients with Different Degrees of Essential Hypertension. Journal of Human Hypertension, 20, 149-155. http://dx.doi.org/10.1038/sj.jhh.1001945

[9] Sathiyapriya, V., Nandeesha, H., Bobby, Z., Selvaraj, N. and Pavithran, P. (2007) Perturbation of Oxidant-Antioxidant Status in Non-Obese Prehypertensive Male Subjects. Journal of Human Hypertension, 21, 176-178. http://dx.doi.org/10.1038/sj.jhh.1002121

[10] Nandeesha, H., Sathiyapriya, V., Bobby, Z., Pavithran, P., Agrawal, A. and Selvaraj, N. (2007) Altered Oxidant Antioxidant Status in Non-Obese Men with Moderate Essential Hypertension. Indian Journal of Medical Sciences, 61, 326-331. http://dx.doi.org/10.4103/0019-5359.32679

[11] Montezano, A.C. and Touyz, R.M. (2012) Molecular Mechanisms of Hypertension-Reactive Oxygen Species and Antioxidants: A Basic Science Update for the Clinician. Canadian Journal of Cardiology, 28, 288-295. http://dx.doi.org/10.1016/j.cjca.2012.01.017

[12] Yu, J.G., Zhou, R.R. and Cai, G.J. (2011) From Hypertension to Stroke: Mechanisms and Potential Prevention Strategies. CNS Neuroscience \& Therapeutics, 17, 577-584. http://dx.doi.org/10.1111/j.1755-5949.2011.00264.x

[13] González-Quevedo, A., García, S.G., Concepción, O.F., Freixas, R.S., Sotolongo, L.Q., Menéndez, M.C., et al. (2011) Increased Serum S-100B and Neuron Specific Enolase-Potential Markers of Early Nervous System Involvement in Essential Hypertension. Clinical Biochemistry, 44, 154-159. http://dx.doi.org/10.1016/j.clinbiochem.2010.11.006

[14] Andreazza, A.C., Cassini, C., Rosa, A.R., Leite, M.C., de Almeida, L.M., Nardin, P., et al. (2007) Serum S100B and Antioxidant Enzymes in Bipolar Patients. Journal of Psychiatric Research, 41, 523-529. http://dx.doi.org/10.1016/j.jpsychires.2006.07.013

[15] Sulaj, M., Saniova, B., Drobna, E. and Schudichova, J. (2009) Serum Neuron Specific Enolase and Malondialdehyde in Patients after Out-Of-Hospital Cardiac Arrest. Cellular and Molecular Neurobiology, 29, 807-810. http://dx.doi.org/10.1007/s10571-009-9361-y

[16] Chobanian, A.V., Bakris, G.L., Black, H.R., Cushman, W.C., Green, L.A., Izzo Jr., J.L., et al. (2003) The Seventh Report of the Joint National Committee on Prevention, Detection, Evaluation, and Treatment of High Blood Pressure: The JNC 7 Report. Journal of the American Medical Association, 289, 2560-2572. http://dx.doi.org/10.1001/jama.289.19.2560

[17] Perloff, D., Grim, C., Flack, J., Frohlich, E.D., Hill, M., McDonald, M., et al. (1993) Human Blood Pressure Determination by Sphygmomanometry. Circulation, 88, 2460-2470. http://dx.doi.org/10.1161/01.CIR.88.5.2460

[18] Aebi, H. (1984) Catalase in Vitro. Methods in Enzymology, 105, 121-126. http://dx.doi.org/10.1016/S0076-6879(84)05016-3

[19] Paglia, D.E. and Valentine, W.N. (1967) Studies on the Quantitative and Qualitative Characterization of Erythrocyte Glutathione Peroxidase. Journal of Laboratory and Clinical Medicine, 70, 158-169.

[20] Carlberg, I. and Mannervik, B. (1985) Glutathione Reductase. Methods in Enzymology, 113, 485-490. http://dx.doi.org/10.1016/S0076-6879(85)13062-4

[21] Pasqualetti, P., Festuccia, V., MacCarone, C., Di Lauro, G. and Casale, R. (1995) Diagnostic Value of Gamma Glutamyltranspeptidase and the Mean Corpuscular Volume in Chronic Hepatitis of Alcoholic Etiology. Minerva Medica, 86, 395-402. 
[22] Halliwell, B. and Gutteridge, J.M. (2007) Free Radicals in Biology and Medicine. Oxford University Press, Oxford.

[23] Mansego, M.L., Solar, Gde, M., Alonso, M.P., Martínez, F., Sáez, G.T., Escudero, J.C., et al. (2011) Polymorphisms of Antioxidant Enzymes, Blood Pressure and Risk of Hypertension. Journal of Hypertension, 29, 492-500. http://dx.doi.org/10.1097/HJH.0b013e328341f1b2

[24] Kedziora-Kornatowska, K., Czuczejko, J., Pawluk, H., Kornatowski, T., Motyl, J., Szadujkis-Szadurski, L., et al. (2004) The Markers of Oxidative Stress and Activity of the Antioxidant System in the Blood of Elderly Patients with Essential Arterial Hypertension. Cellular and Molecular Biology Letters, 9, 635-641.

[25] Chaves, F.J., Mansego, M.L., Blesa, S., Gonzalez-Albert, V., Espinosa, O., Giner, V., et al. (2007) Inadequate Cytoplasmic Antioxidant Enzymes Response Contributes to the Oxidative Stress in Human Hypertension. American Journal of Hypertension, 20, 62-69. http://dx.doi.org/10.1016/j.amjhyper.2006.06.006

[26] Wassmann, S., Wassmann, K. and Nickenig, G. (2004) Modulation of Oxidant and Antioxidant Enzyme Expression and Function in Vascular Cells. Hypertension, 44, 381-386. http://dx.doi.org/10.1161/01.HYP.0000142232.29764.a7

[27] Rybka, J., Kupczyk, D., Kędziora-Kornatowska, K., Czuczejko, J., Szewczyk-Golec, K., Motyl, J., et al. (2011) Glutathione-Related Antioxidant Defense System in Elderly Patients Treated for Hypertension. Cardiovascular Toxicology, 11, 1-9. http://dx.doi.org/10.1007/s12012-010-9096-5

[28] Kędziora-Kornatowska, K., Czuczejko, J., Szewczyk-Golec, K., Motyl, J., Szadujkis-Szadurski, L., Kornatowski, T., et al. (2006) Effects of Perindopril and Hydrochlorothiazide on Selected Indices of Oxidative Stress in the Blood of Elderly Patients with Essential Hypertension. Clinical and Experimental Pharmacology and Physiology, 33, 751-756. http://dx.doi.org/10.1111/j.1440-1681.2006.04436.X

[29] Kaminsky, Y., Suslikov, A. and Kosenko, E. (2010) Specific and Pronounced Impacts of Lisinopril and Lisinopril plus Simvastatin on Erythrocyte Antioxidant Enzymes. The Journal of Clinical Pharmacology, 50, 180-187. http://dx.doi.org/10.1177/0091270009344854

[30] Hashimoto, R., Umemoto, S., Guo, F., Umeji, K., Itoh, S., Kishi, H., et al. (2010) Nifedipine Activates PPAR Gamma and Exerts Antioxidative Action through Cu/ZnSOD Independent of Blood-Pressure Lowering in SHRSP. Journal of Atherosclerosis and Thrombosis, 17, 785-795. http://dx.doi.org/10.5551/jat.4556

[31] Weseler, A.R. and Bast, A. (2010) Oxidative Stress and Vascular Function: Implications for Pharmacologic Treatments. Current Hypertension Reports, 12, 154-161. http://dx.doi.org/10.1007/s11906-010-0103-9

[32] Jiang, Z., Akey, J.M., Shi, J., Xiong, M., Wang, Y., Shen, Y., et al. (2001) A Polymorphism in the Promoter Region of Catalase is Associated with Blood Pressure Levels. Human Genetics, 109, 95-98. http://dx.doi.org/10.1007/s004390100553

[33] Medina-Hernández, V., Ramos-Loyo, J., Luquin, S., Sánchez, L.F., García-Estrada, J. and Navarro-Ruiz, A. (2007) Increased Lipid Peroxidation and Neuron Specific Enolase in Treatment Refractory Schizophrenics. Journal of Psychiatric Research, 41, 652-658. http://dx.doi.org/10.1016/j.jpsychires.2006.02.010

[34] Góth, L. (1991) A Simple Method for Determination of Serum Catalase Activity and Revision of Reference Range. Clinica Chimica Acta, 196, 143-152. http://dx.doi.org/10.1016/0009-8981(91)90067-M

[35] Zhou, X.F., Cui, J., DeStefano, A.L., Chazaro, I., Farrer, L.A., Manolis, A.J., et al. (2005) Polymorphisms in the Promoter Region of Catalase Gene and Essential Hypertension. Disease Markers, 21, 3-7. http://dx.doi.org/10.1155/2005/487014

[36] Onat, A., Hergenç, G., Karabulut, A., Türkmen, S., Doğan, Y., Uyarel, H., et al. (2006) Serum Gamma Glutamyltransferase as a Marker of Metabolic Syndrome and Coronary Disease Likelihood in Nondiabetic Middle-Aged and Elderly Adults. Preventive Medicine, 43, 136-139. http://dx.doi.org/10.1016/j.ypmed.2006.04.005

[37] Cheung, B.M., Ong, K.L., Tso, A.W., Cherny, S.S., Sham, P.C., Lam, T.H., et al. (2011) Gamma-Glutamyltransferase Level Predicts the Development of Hypertension in Hong Kong Chinese. Clinica Chimica Acta, 412, 1326-1331. http://dx.doi.org/10.1016/j.cca.2011.03.030

[38] Mason, J.E., Starke, R.D. and Van Kirk, J.E. (2010) Gamma-Glutamyltransferase: A Novel Cardiovascular Risk Biomarker. Preventive Cardiology, 13, 36-41. http://dx.doi.org/10.1111/j.1751-7141.2009.00054.X

[39] Shimizu, Y., Imano, H., Ohira, T., Kitamura, A., Kiyama, M., Okada, T., et al. (2010) Gamma-Glutamyltranspeptidase and Incident Stroke among Japanese Men and Women: The Circulatory Risk in Communities Study (CIRCS). Stroke, 41, 385-388. http://dx.doi.org/10.1161/STROKEAHA.109.569061

[40] Lee, D.H., Jacobs Jr., D.R., Gross, M., Steffes, M., et al. (2003) Gamma-Glutamyltransferase is a Predictor of Incident Diabetes and Hypertension: The Coronary Artery Risk Development in Young Adults (CARDIA) Study. Clinical Chemistry, 49, 1358-1366. http://dx.doi.org/10.1373/49.8.1358

[41] Shankar, A. and Li, J. (2007) Association between Serum Gamma-Glutamyltransferase Level and Prehypertension among US Adults. Circulation Journal, 71, 1567-1572. http://dx.doi.org/10.1253/circj.71.1567

[42] Juranek, J.K., Aleshin, A., Rattigan, E.M., Johnson, L., Qu, W., Song, F., et al. (2010) Morphological Changes and 
Immunohistochemical Expression of RAGE and Its Ligands in the Sciatic Nerve of Hyperglycemic Pig (Sus Scrofa). Biochemistry Insights, 1, 47-59. http://dx.doi.org/10.4137/BCI.S5340

[43] Aviles-Reyes, R.X., Angelo, M.F., Villarreal, A., Rios, H., Lazarowski, A. and Ramos, A.J. (2010) Intermittent Hypoxia during Sleep Induces Reactive Gliosis and Limited Neuronal Death in Rats: Implications for Sleep Apnea. Journal of Neurochemistry, 112, 854-869. http://dx.doi.org/10.1111/j.1471-4159.2009.06535.x

[44] Sorci, G., Riuzzi, F., Agneletti, A.L., Marchetti, C. and Donato, R. (2004) S100B Causes Apoptosis in a Myoblast Cell Line in a RAGE-Independent Manner. Journal of Cellular Physiology, 199, 274-283. http://dx.doi.org/10.1002/jcp.10462

[45] Hamed, S.A., Hamed, E.A. and Zakary, M.M. (2009) Oxidative Stress and S-100B Protein in Children with Bacterial Meningitis. BMC Neurology, 9, 51. http://dx.doi.org/10.1186/1471-2377-9-51

[46] Tskitishvili, E., Sharentuya, N., Temma-Asano, K., Mimura, K., Kinugasa-Taniguchi, Y., Kanagawa, T., et al. (2010) Oxidative Stress-Induced S100B Protein from Placenta and Amnion Affects Soluble Endoglin Release from Endothelial Cells. Molecular Human Reproduction, 16, 188-199. http://dx.doi.org/10.1186/1471-2377-9-51 